\title{
Standar Operasional Prosedur Kantor Imigrasi Dalam Penanganan Wisatawan Asing Yang Menyalahgunakan Izin Tinggal Kunjungan Di Bali
}

\author{
Muhammad Itsar Susilo a, 1 , Gde Indra Bhaskara ${ }^{\text {a, } 2}$ \\ 1 itsarsusilo@gmail.com , ${ }^{2}$ gbhaskara@unud.ac.id \\ a Program Studi Sarjana Destinasi Pariwisata, Fakultas Pariwisata,Universitas Udayana, Jl. Dr. R. Goris, Denpasar, Bali 80232 Indonesia
}

\begin{abstract}
This research was conducted to seek the Standard Operating Procedures of the Immigration Office in Handling Foreign Tourists Who Misused Permits for Visiting Visa in Bali.

The research used in study is qualitative descriptive. The informant determination technique used was the Purposive Procedure technique. The data sources used were primary and secondary data sources. Primary data in this study were data that come from direct observation to the location of the study by observation and interview. While secondary data in this study were data obtained from documentation or literature studies to supplement primary data.

The results showed that the supervision and deportation of foreign nationals at the Ngurah Rai Special Class I Immigration Office was carried out to the maximum by immigration officers, starting from the coming till being out of Indonesia, the process was in accordance with Law Number 6 of 2011 and Regulations The Government of the Republic of Indonesia Number 31 of 1994 concerning Procedures for Supervision of Foreigners and Immigration Measures as well as provisions that apply to the stages of foreigners is carried out by the process of detention in the detention room of the Immigration Office, given the action by the Head of the Immigration Office.
\end{abstract}

Keywords: Immigration Office, Foreign Tourists, Visa Permits.

\section{PENDAHULUAN}

Indonesia tercatat negara yang memiliki 17504 buah pulau. Selain itu, Indonesia merupakan negara persinggahan karena wilayahnya dinilai sangat strategis dan menjadi akses wisatawan asing untuk masuk ke dalam Indonesia maupun keluar Indonesia. Akan tetapi Indonesia kurang memadai dalam mengatur perpindahan manusia ini. Jalan masuk untuk memasuki wilayah Indonesia memiliki beberapa cara mulai dengan melalui bandara ataupun melalui dengan pelabuhan kapal yang tersebar hampir diseluruh Indonesia sehingga pemerintah dalam mengontrol batasan - batasan perpindahan manusia sangatlah sulit.

Pemeriksaan atau pengecekan perpindahan manusia ini hanya dapat dilakukan oleh otoritas lembaga imigrasi. Lembaga imigrasi memiliki peran penting dalam hal ini, mengingat lembaga ini adalah ujung tombak dalam pengecekan perpindahaan manusia untuk dapat memasuki wilayah Indonesia. akan tetapi pemeriksaan atau pengecekan ini pada realistisnya dilapangan tidak sesuai dengan harapan, karena masih banyak kegiatan perpindahan manusia ini yang tidak diawasai secara maxsimal. Fungsi kantor imigrasi adalah memberikan pelayanan kepada masyarakat dan wisatawan asing. Kantor imigrasi memberi pelayanan dalam mengurusan hal - hal berupa surat perjalanan, surat izin tinggal dan status lintas batas, penyidikan, kerjasama luar negeri, penindakan, visa, intelijen, dan sistem informasi.

Bali adalah pulau di Indonesia yang pemeriksaan atau pengecekannya tidak terlalu ketat tentang perpindahan manusia. Pulau Bali adalah salah satu pulau destinasi utama Indonesia. Bali mempunyai kombinasi antara keindahan alam dan adat istiadat masyarakat yang ramah dan eksotis. Paduan itu membuat wisatawan asing tertarik untuk mendatangi ke Bali.

Letak Bali yang strategis dan banyak hal unik menjadikan Bali sebagai pusat perpindahan manusia baik memasuki wilayah atau keluar wilayah Indonesia, yang dimana dalam hal ini adalah wisatawan asing yang sedang ingin berlibur ke Bali, akan tetapi wisatawan asing ini sering luput dalam penyalahgunaan surat dokumen izin tinggal.

\section{TINJAUAN PUSTAKA}

Telaah penelitian sebelumnya sangat penting dilakukan untuk membandingkan antara 
penelitan sebelumnya dengan penelitian yang akan dilakukan berdasarkan fokus penelitian sehingga tidak terjadi penelitian ganda, serta untuk mengetahui apa keunggulan atau posisi dari yang sekarang diteliti dan dibandingkan memakai penelitian yang sudah ada. Berdasarkan telaah penelitian sebelumnya yang pertama terkait dengan fokus, yaitu "Kinerja Kantor Imigrasi Kelas I Pekanbaru Dalam Pengawasan Imigran Ilegal Di Kota Pekanbaru (Limbong, 2016)". Penelitian kedua yaitu "Pengawasan Keimigrasian Terhadap Orang Asing Dalam Rangka Pendeportasian Ditinjau Dari UndangUndang Nomor 6 Tahun 2011 Tentang Keimigrasian (Bahri 2016)".

Penelitian ini menggunakan beberapa hal konsep sebagai panduan analisis bagi penelitian agar tau batasan - batasan dari penelitan tersebut. Konsep - konsep tersebut sebagai berikut: Wisatawan adalah seseorang yang mendatangi suatu negara asing dengan berbagai maksud dan tujuan. Asalkan bukan untuk menetap selamanya atau untuk usaha - usaha teratur melintas perbatasan di negara yang didatanginya. Uang yang didapatkan juga bukan dari hasil negara tersebut, melainkan uang tersebut dibawa dari negara asalnya. Dalam bahasa Inggris wisatawan itu disebut tourist (Yoeti, 1992:142).

Standar Operasional Prosedur adalah deretan rangkaian suatu kegiatan atau tugas tugas yang harus dikerjakan dalam pekerjaan, yang dimana kegiatan - kegiatan tersebut saling berhubungan dengan apa yang dilakukannya, caranya melakukannya, tempatnya melakukan, dan siapa saja yang melakukannya. (Moekijat, 2008).

Imigrasi adalah proses perpindahan manusia dari suatu negara atau bansa ke wilayah lain dengan tujuan untuk menetap secara permanen, dimana orang tersebut bukanlah warga negara dari negara yang dituju dan mencari nafkah di negara tersebut. Keimigrasian adalah tindakan administrasi dari kegiatan litas orang yang masuk dan keluar serta pengawasan untuk menjaga keedaulatan dalam berbangsan dan bernegara secara baik serta menjunjung tinggi keadilan dan kemakmuran bagi seluruh masyarakat yang sesuai dengan Pancasila dan UUD RI.
Pelayanan merupakan pemenuhan suatu kebutuhan dengan cara kegiatan orang lain secara langsung baik berupa pelayanan barang ataupun pelayanan jasa. Definisi pelayanan secara mendalam adalah suatu kegiatan untuk menolong orang lain untuk membuat atau memberikan waktu, bentuk, kebutuhan, keperluan, dan tempat untuk seseorang (Murdic, 1990)".

\section{METODE PENELITIAN}

Sumber data penelitian yang digunakan adalah sebagai berikut: data primer dan data sekunder. Data primer merupakan sumber data yang diberikan secara langsung kepada peneliti. Data tersebut meliputi data yang belum dipublikasikan dan didapatkan secara langsung oleh sumber pertama melalui teknik pengumpulan data dari observasi dan wawancara tidak terstruktur. Data primer yang dipergunakan dalam penelitian ini yaitu gambaran umum kantor imigrasi dan SOP kantor imgrasi.

Data sekunder adalah data yang didapatkan secara tidak langsung oleh peneliti, seperti halnya data tersebut didapatkan lewat orang lain atau berupa dokumen peneliti terdahulu yang bersangkutan dengan yang akan diteliti. Data sekunder didapatkan dalam penelitian ini yaitu profil kantor imigrasi dan jumlah wisatawan asing yang menyalahgunakan izin tinggal di Bali.

Metode pengumpulan data dalam penelitian ini, adalah: observasi, wawancara dan studi perpustaka. Observasi dilakukan untuk mengamati secara langsung kinerja pegawa kantor Imigrasi terhadap wisatawan asing yang meyalahgunakan izin tinggal. Wawancara dilakukan untuk memperoleh data mengenai jumlah wisatawan asing yang menyalahgunakan izin tinggal. Studi perpustakaan untuk mendapatkan data mengenai monografi Kantor Imigrasi.

Teknik analisis model ini digunakan pada waktu - waktu tertentu saja, setelah selesai mengumpulkan data. Peneliti akan menjabarkan dan mereduksi data terhadap jawaban informan pada saat wawancara, jika jawaban dirasa belum memuaskan maka peneliti akan melanjutkan lagi sampai data dianggap kredibel. 
Penelitian yang dilakukan mempergunakan kualitatif. Data didapatkan menggunakan wawancara dengan cara menanyakan berupa uraian keadaan kondisi fisik dari kantor Imigrasi, fasilitas yang tersedia, monografi dan kebijakan terkait kantor Imigrasi secara keseluruhan. Hasil wawancara dalam penelitian dipergunakan sebagai sumber data utama untuk menjawab penelitian. Analisis data pertama - tama dengan melakukan wawancara secara mendalam dengan informan. Setelah melakukan wawancara, peneliti membuat transkip hasil wawancara dengan cara memutar kembali rekaman wawancara kemudian menuliskan kata- kata yang sesuai dengan apa yang ada direkaman tersebut. Setelah peneliti menulis hasil wawancara ke dalam transkip, selanjutnya peneliti memilih hal-hal yang pokok, memfokuskan pada hal-hal yang penting, di cari tema dan polanya sehingga memberikan gambaran yang lebih jelas kepada peneliti dan mengabaikan data yang tidak diperlukan

\section{HASIL DAN PEMBAHASAN}

\subsection{Gambaran Umum}

\subsubsection{Kantor Imigrasi Kelas 1 Khusus Ngurah Rai}

Wisatawan asing untuk dapat memasuki wilayah Indonesia terutama di pulau Bali harus sesuai dengan ketentuan-ketentuan dari pemerintah. Oleh karena itu dibutuhkan pengawasan terhadap kegiatan ke luar masuknya wisatawan asing beserta kelengkapannya, seperti pengecekan data perjalanan (paspor dan visa) akan oleh lembaga keimigrasian. Di Pulau Bali, salah satu Lembaga otoritas yang berwenang melakukan pengawasan perpindahan wisatawan masuk dan keluar Pulau Bali adalah Kantor Imigrasi Kelas 1 Khusus Ngurah Rai.

\subsection{Standar Operasional Prosedur}

Standar Operasional Prosedur (SOP) adalah instrument pendukung dalam mewujudkan tujuan dan mendapatkan hasil pekerjaan yang paling praktis dari para pekerja sesuai berlandaskan ketentuan Direktur Jenderal Imigrasi No: IMI-GR.01.09-1104 26 Maret Tahun 2013. SOP Kantor Imigrasi terlampir pada table 4.1:
Tabel 4.1

Standar Oprasional Prosedur Kantor Imigrasi Kelas 1 Khusus Ngurah Rai Dalam Pembuatan Surat Izin Tinggal

\begin{tabular}{|c|c|c|c|c|c|}
\hline No & Kegiatan & $\begin{array}{l}\text { Keleng } \\
\text { kapan }\end{array}$ & $\begin{array}{c}\text { Wakt } \\
\mathbf{u}\end{array}$ & $\begin{array}{c}\text { Outpu } \\
\text { t }\end{array}$ & Keterangan \\
\hline 1 & $\begin{array}{l}\text { Menerima } \\
\text { pemohonan, } \\
\text { memeriksa } \\
\text { kelengkapan } \\
\text { persaratan, } \\
\text { dan } \\
\text { memberikan } \\
\text { tanda terima } \\
\text { permohonan }\end{array}$ & $\begin{array}{l}\text { Berkas } \\
\text { pemoh } \\
\text { onan } \\
\text { dan } \\
\text { dokum } \\
\text { en }\end{array}$ & $\begin{array}{c}10 \\
\text { menit }\end{array}$ & $\begin{array}{l}\text { Tanda } \\
\text { terima } \\
\text { pemoh } \\
\text { onan }\end{array}$ & $\begin{array}{c}\text { Persyaratan } \\
\text { pemohonan } \\
\text { sesuai } \\
\text { peraturan } \\
\text { yang berlaku }\end{array}$ \\
\hline 2 & $\begin{array}{l}\text { Memasukkan } \\
\text { data } \\
\text { pemohon ke } \\
\text { aplikasi Izin } \\
\text { Tinggal }\end{array}$ & $\begin{array}{l}\text { Berkas } \\
\text { pemoh } \\
\text { onan } \\
\text { dan } \\
\text { dokum } \\
\text { en }\end{array}$ & $\begin{array}{c}5 \\
\text { menit }\end{array}$ & $\begin{array}{c}\text { Data } \\
\text { pemoh } \\
\text { on di } \\
\text { kompu } \\
\text { ter }\end{array}$ & \\
\hline 3 & $\begin{array}{l}\text { Memeriksa } \\
\text { data } \\
\text { pemohon } \\
\text { pada daftar } \\
\text { cekal }\end{array}$ & $\begin{array}{l}\text { Berkas } \\
\text { pemoh } \\
\text { onan } \\
\text { dan } \\
\text { dokum } \\
\text { en }\end{array}$ & $\begin{array}{c}5 \\
\text { menit }\end{array}$ & $\begin{array}{l}\text { Verifik } \\
\text { asi } \\
\text { data } \\
\text { cukai } \\
\text { pemoh } \\
\text { on }\end{array}$ & $\begin{array}{c}\text { Apabila } \\
\text { masuk dalam } \\
\text { daftar cekal } \\
\text { ditindaklanju } \\
\text { ti pada jalur } \\
\text { SOP Cukai }\end{array}$ \\
\hline 4 & $\begin{array}{c}\text { Meneliti } \\
\text { keabsahan } \\
\text { dokumen } \\
\text { dan } \\
\text { penjamin }\end{array}$ & $\begin{array}{l}\text { Dokum } \\
\text { en dan } \\
\text { paspor }\end{array}$ & $\begin{array}{c}5 \\
\text { menit }\end{array}$ & $\begin{array}{c}\text { Tanda } \\
\text { tangan } \\
\text { pada } \\
\text { dokum } \\
\text { en dan } \\
\text { paspor }\end{array}$ & \\
\hline 5 & $\begin{array}{l}\text { Melakukan } \\
\text { pemindaian } \\
\text { dokumen } \\
\text { pemohonan }\end{array}$ & $\begin{array}{l}\text { Berkas } \\
\text { pemoh } \\
\text { onan } \\
\text { dan } \\
\text { dokum } \\
\text { en } \\
\end{array}$ & $\begin{array}{c}10 \\
\text { menit }\end{array}$ & $\begin{array}{l}\text { Data } \\
\text { hasil } \\
\text { pindai } \\
\text { dokum } \\
\text { en }\end{array}$ & \\
\hline 6 & $\begin{array}{l}\text { Melakukan } \\
\text { penelitian } \\
\text { data dan } \\
\text { informasi } \\
\text { serta } \\
\text { memberikan } \\
\text { persetujuan } \\
\text { oleh pejabat } \\
\text { berwenang } \\
\end{array}$ & $\begin{array}{l}\text { Tanda } \\
\text { terima } \\
\text { pemoh } \\
\text { onan }\end{array}$ & $\begin{array}{c}5 \\
\text { menit }\end{array}$ & $\begin{array}{l}\text { Paraf } \\
\text { perset } \\
\text { ujuan }\end{array}$ & $\begin{array}{c}\text { Apabila ada } \\
\text { ketidaksesua } \\
\text { ian } \\
\text { dilanjutkan } \\
\text { pada alur } \\
\text { SOP } \\
\text { ketidaksesua } \\
\text { ian }\end{array}$ \\
\hline 7 & $\begin{array}{c}\text { Menerima } \\
\text { pembayaran } \\
\text { sesuai } \\
\text { pemohonan } \\
\text { dan } \\
\text { memberikan } \\
\text { tanda bukti } \\
\text { bayar } \\
\end{array}$ & $\begin{array}{l}\text { Slip } \\
\text { tanda } \\
\text { bukti } \\
\text { pemba } \\
\text { yaran }\end{array}$ & $\begin{array}{c}5 \\
\text { menit }\end{array}$ & $\begin{array}{l}\text { Hasil } \\
\text { pemba } \\
\text { yaran } \\
\text { ITK }\end{array}$ & $\begin{array}{c}\text { Tanda bukti } \\
\text { bayar } \\
\text { digunakan } \\
\text { untuk } \\
\text { pengambilan } \\
\text { dokumen } \\
\text { selesai }\end{array}$ \\
\hline 8 & $\begin{array}{l}\text { Melakukan } \\
\text { pengambilan } \\
\text { foto dan } \\
\text { sidik jari } \\
\text { pemohon } \\
\text { sebagai data } \\
\text { biometrik }\end{array}$ & $\begin{array}{l}\text { Slip } \\
\text { tanda } \\
\text { bukti } \\
\text { pemba } \\
\text { yaran }\end{array}$ & $\begin{array}{c}10 \\
\text { menit }\end{array}$ & $\begin{array}{c}\text { Foto } \\
\text { biomet } \\
\text { rik dan } \\
\text { sidik } \\
\text { jari } \\
\text { pemoh } \\
\text { on }\end{array}$ & \\
\hline
\end{tabular}


Vol. 7 No 1, 2019

\begin{tabular}{|c|c|c|c|c|c|}
\hline 9 & $\begin{array}{c}\text { Memberikan } \\
\text { nomer } \\
\text { register dan } \\
\text { menerakan } \\
\text { Izin Tinggal } \\
\text { Kunjungan } \\
\text { pada paspor } \\
\text { pemohon }\end{array}$ & $\begin{array}{l}\text { Berkas } \\
\text { pemoh } \\
\text { onan } \\
\text { dan } \\
\text { dokum } \\
\text { en }\end{array}$ & $\begin{array}{c}3 \\
\text { menit }\end{array}$ & $\begin{array}{c}\text { Nomor } \\
\text { registe } \\
\text { r } \\
\text { pemoh } \\
\text { on } \\
\text { dalam } \\
\text { sistem }\end{array}$ & \\
\hline 10 & $\begin{array}{c}\text { Memberikan } \\
\text { Dokumen } \\
\text { perizinan } \\
\text { kepada } \\
\text { kepala } \\
\text { kantor }\end{array}$ & $\begin{array}{c}\text { Dokum } \\
\text { en }\end{array}$ & $\begin{array}{c}5 \\
\text { menit }\end{array}$ & $\begin{array}{c}\text { Tanda } \\
\text { tangan } \\
\text { pada } \\
\text { dokum } \\
\text { en dan } \\
\text { paspor }\end{array}$ & $\begin{array}{c}\text { Pengesahan } \\
\text { dilakukan } \\
\text { dengan } \\
\text { ditandatanga } \\
\text { ni petugas } \\
\text { atau kepala } \\
\text { kantor } \\
\end{array}$ \\
\hline 11 & $\begin{array}{c}\text { Mamasukan } \\
\text { fotokopi data } \\
\text { dokumen } \\
\text { yang } \\
\text { memiliki izin } \\
\text { tinggal } \\
\text { sebagai data } \\
\text { kantor } \\
\end{array}$ & $\begin{array}{l}\text { Dokum } \\
\text { en dan } \\
\text { paspor }\end{array}$ & $\begin{array}{l}10 \\
\text { mmen } \\
\text { it }\end{array}$ & $\begin{array}{l}\text { Data } \\
\text { hasil } \\
\text { pindai } \\
\text { dokum } \\
\text { en }\end{array}$ & $\begin{array}{c}\text { Koreksi data } \\
\text { pada sistem } \\
\text { bila perlu }\end{array}$ \\
\hline 12 & $\begin{array}{l}\text { Menyerahka } \\
\text { n dokumen } \\
\text { keimigrasian } \\
\text { yang telah } \\
\text { selesai } \\
\text { kepada } \\
\text { pemohon }\end{array}$ & $\begin{array}{l}\text { Bukti } \\
\text { pemba } \\
\text { yaran }\end{array}$ & $\begin{array}{c}5 \\
\text { menit }\end{array}$ & $\begin{array}{c}\text { Paspor } \\
\text { yang } \\
\text { ditara } \\
\text { kan } \\
\text { cap } \\
\text { ITK }\end{array}$ & $\begin{array}{c}\text { Pemohon } \\
\text { menunjukan } \\
\text { tanda bukti } \\
\text { bayar } \\
\text { sebagai } \\
\text { syarat } \\
\text { pengambilan } \\
\text { dokumen }\end{array}$ \\
\hline 13 & $\begin{array}{l}\text { Menyerahka } \\
\text { n berkas } \\
\text { pemohonan } \\
\text { yang telah } \\
\text { selesai untuk } \\
\text { dilakukan } \\
\text { pengarsipan }\end{array}$ & $\begin{array}{c}\text { Berkas } \\
\text { selesai } \\
\text { dan } \\
\text { eksped } \\
\text { isi } \\
\text { insarko } \\
\text { m } \\
\end{array}$ & $\begin{array}{c}5 \\
\text { menit }\end{array}$ & $\begin{array}{l}\text { Arsip } \\
\text { berkas } \\
\text { selesai }\end{array}$ & \\
\hline
\end{tabular}

Sumber: Data lapangan 2018

\section{Pengisian Biodata}

Terlebih dahulu wisatawan asing diberikan formulir biodata diri dengan ketentuan yang sudah dibuat di kolom pengisian. Pengisian biodata diri ini juga dapat di akses melalu website yang telah disediakan. Untuk pengisian biodata diri melalu website diwajibkan untuk mencetaknya sebagai tanda bukti telah mengisi biodata diri ke petugas.

\section{Nomer Antrian}

Setelah pengisian biodata diri, wisatawan diarahkan untuk mengambil nomer antrian terlebih dahulu agar tertib sesuai dengan urutan. Untuk mengetahui nomer antrian dapat melihat ke arah monitor layar yang berupa penampilan angka.

\section{$>$ Memberikan Data SITKRI}

Setelah nomer antrian dilayar monitor sudah sesuai dengan nomer antrian yang wisatawan pegang, wisatawan memberikan formulir biodata diri yang sudah diisi atau dicetaknya kepada petugas sebagai tanda bukti.

Setelah diterima biodata diri wisatawan, petugas akan mengecek terlebih dahulu biodatanya apakah sudah sesuai pengisiannya atau tidak dengan kolom pengisian biodata.

Apabila biodata tidak sesuai dengan kolom pengisian, biodata diri akan dikembalikan ke wisatawan untuk dapat melengkapi terlebih dahulu biodata yang belum lengkap.

Sedangkan kalo biodata sudah memenuhi sara kelengkapan yang sudah ditetapkan, maka petugas akan memberikan surat pengajuan pembayaran yang sesuai dengan ketentuan.

\section{Melakukan Pembayaran}

Setelah menerima surat pengajuan pembayaran, wisatawan diharuskan melakukan pembayaran terlebih dahulu. Setelah wisatawan melakukan pembayaran, wisatawan akan diberi tanda terima pembayaran berupa kuwitansi pembayaran.

\section{$>$ Melakukan Foto dan scan Sidik Jari}

Wisatawan wajib hadir pada saat melakukan pengambilan fhoto dan scan sidik jari.

Petugas akan mengarahkan wisatawan untuk sesi fhoto dan scan jari sesuai dengan nomer panggilan. Dalam pengamabilan foto wisatawan harus menghadap kekamera serta dilarang untuk menggunakan topi dan kacamata. Setelah itu petugas meminta 
wisatawan untuk menempelkan satu persatu ke sepuluh jari tangannya untuk melakukan scan sidik jari.

Apabila ada kelainan cacat fisik atau sistem komputer yang sedang error makan petugas akan membuat catatan keterangan pada kolom petugas.

Serta apabila wisatawan yang mengajukan diri anak - anak dibawah usia 3 tahun maka tidak diperlukan pengambilan scan sidik jari bagi anak tersebut.

\section{Pencetakan SITKRI}

Setelah semua prosedur telah dilakukan oleh wisatawan, petugas akan menyetak SITKRI secara resmi dan diberikan laminasi blangko SITKRI.

Apabila laminasi blangko SITKRI mengalami kecacatan atau kualitas yang jelek maka dapat melakukan pergantian blanko baru secara gratis tanpa dipumut biaya lagi.

\section{$>$ Penandatanganan SITKRI}

Selanjutnta SITKRI akan diberikan kepada pejabat yang berwenang yaitu kepala bidang atau kepala kantor untuk diberikan persetujuan SITKRI dengan cara di tanda tangani dan diberikan tanda cap stempel dinas.

\section{Memberikan SITKRI}

Petugas akan meminta wisatawan untuk melakukan tanda tangan di kolom penerimaan sebagai tanda bukti telah diserahkan SITKRI dari petugas kepada wisatawan yang mengajukan.

Tabel 4.2

Analisis Praktis dan Tidak Praktis Standar Oprasional Prosedur Kerja Imigrasi Kelas I Khusus Ngurah Rai

\begin{tabular}{|c|l|r|l|}
\hline No & Rangkaian Kegiatan & Praktis & $\begin{array}{l}\text { Tidak } \\
\text { Praktis }\end{array}$ \\
\hline 1 & $\begin{array}{l}\text { Data pemohon diterima } \\
\text { dan diperiksa } \\
\text { keseluruhan }\end{array}$ & $\checkmark$ & \\
\hline
\end{tabular}

\begin{tabular}{|c|l|c|c|} 
& $\begin{array}{l}\text { persyaratan, lalu } \\
\text { dimasukan data kedalam } \\
\text { komputer, proses arsip } \\
\text { dan print data } \\
\text { permohonan }\end{array}$ & & \\
\hline 2 & $\begin{array}{l}\text { Diberikan pengesahan } \\
\text { oleh kepala kantor atau } \\
\text { petugas yang } \\
\text { mempunyai wewenang }\end{array}$ & $\checkmark$ & \\
\hline 3 & $\begin{array}{l}\text { Turun langsung untuk } \\
\text { memberikan sensus } \\
\text { imigrasi kepada } \\
\text { wisatawan asing, dengan } \\
\text { catatan adanya surat } \\
\text { utusan dari kepala } \\
\text { kantor }\end{array}$ & & \\
\hline 4 & $\begin{array}{l}\text { Membayar sesuai } \\
\text { dengan nominal yang } \\
\text { ditentukan oleh petugas }\end{array}$ & $\checkmark$ & \\
\hline & $\begin{array}{l}\text { Mewawancarai, } \\
\text { identifikasi data, } \\
\text { membenarkan data dan } \\
\text { melakukan pengecekan } \\
\text { berupa fhoto serta scan } \\
\text { jari }\end{array}$ & $\checkmark$ & \\
\hline 6 & $\begin{array}{l}\text { Memberikan surat ke } \\
\text { wisatawan }\end{array}$ & $\checkmark$ & \\
\hline 7 & $\begin{array}{l}\text { Persetujuan petugas } \\
\text { kantor atau kepala } \\
\text { kantor }\end{array}$ & $\checkmark$ & \\
\hline 8 & Memproses dokumen & \\
\hline 9 & Memberikan dokumen & $\checkmark$ & \\
\hline $54 m$ ber: Data lapangan 2018 & & \\
\hline
\end{tabular}

Sumber: Data lapangan 2018

Data diatas adalah rangkaian prosedur dalam pembuatan surat izin tinggal oleh petugas Kantor Imigrasi Kelas 1 Khusus Ngurah Rai. Hasil praktis dan tidak praktis data penelitian tersebut adalah hasil dari penglihatan peneliti selama melakakukan penelitian. Berdasarkan data tersebut menyatakan bahwa masih ada rangkaian kegiatan yang dinilai masih kurang tidak praktis yaitu pada kegiatan nomer 3 .

\section{PENUTUP}

\subsection{Kesimpulan}

Berdasakan hasil penulisan mengenai SOP Kantor Imigrasi Dalam Penanganan Wisatawan Asing Yang Menyalahgunakan Izin Tinggal Kunjungan dapat disimpulkan bahwa: 
1. Kantor Imigrasi Kelas 1 Khusus Ngurah Rai ditetapkan pada bulan oktober 1980 dengan cakupan wilayah Bali. Dengan ditetapkannya Kantor Wilayah Departemen Kehakiman Propinsi Bali pada tahun 1982 berubah menjadi Kantor Imigrasi Kelas 1 Khusus Ngurah Rai.

2. Syarat dan ketentuan dalam prosedur Kantor Imigrasi sudah sama dengan prosedur yang diterapkan, akan tetapi ada kegiatan prosedur yang dinilai kurang efisien bila dilakukan karena kurangnya faktor fasilitas kenyamanan untuk petugas yang bekerja.

\section{A. Saran}

Saran Untuk Dinas Kantor Imigrasi Khusus 1 Ngurah Rai.

- Dapat lebih memberikan kualitas yang terbaik dalam memberikan pelayanan terhadap wisatawan asing.

- Meningkatkan pemeriksaan izin tinggal terhadap wisatawan asing.

\section{DAFTAR PUSTAKA}

Amir, Y. P., 2003. Hipersemiotika: Tafsir Cultural Studies Atas Matinya Makna. Yogyakarta: Jalasutra.

Burhan, B., 2007. Penelitian kualitatif; Komunikasi, Ekonomi, Kebijakan Publik, dan Ilmu Sosial Lainnya. Jakarta: Kencana.

Creswell, J. W., 2012. Motode Penelitian Kualitatif. Research design: pendekatan kualitatif, kuantitatif, dan mixed, Volume 1, pp. 342-358.

Fuad, M. \& Paulus, N. S., 2006. Pengantar Bisnis. Jakarta: Gramedia Pustaka Utama.

Lexy, J. \& Moleong, 2005. Metodologi Penelitian Kualitatif. Bandung: Remaja Rosdakarya.

Limbong, R. A., 2016. Organizational Performance and Monitoring. Kinerja Kantor Imigrasi Kelas I Pekanbaru Dalam Pengawasan Imigran Ilegal Di Kota Pekanbaru, 2 Oktober, Volume 3, pp. 4-8.

Moekijat, 2008. Administasi Perkantoran. Jakarta: Mandar Maju.

Sugiyono, 2008. Metode penelitian pendidikan:(pendekatan kuantitatif, kualitatif dan $R \& D$ ). Bandung: Alfabeta.
Yoeti, 0. A., 1982. Perencanaan Strategis Pemasaran daerah Tujuan Wisata. Jakarta: Pradnya Paramita.

Yoeti, 0. A., 2003. Pengantar Ilmu Pariwisata. Bandung: Angkasa. 